$04 ; 12$

\title{
Филаментация и самофокусировка электронных пучков в вакуумных и газовых диодах
}

\author{
() В.И. Олешко ${ }^{1,2}$, В.Ф. Тарасенко ${ }^{1,2}$, А.Г. Бураченко ${ }^{1}$, V.V. Nguyen $^{2}$ \\ ${ }^{1}$ Институт сильноточной электроники СО РАН, Томск, Россия \\ ${ }^{2}$ Национальный исследовательский Томский политехнический университет, Томск, Россия \\ E-mail: oleshko@tpu.ru
}

Поступило в Редакцию 12 декабря 2018г.

В окончательной редакции 12 декабря 2018г.

Принято к публикации 27 декабря 2018г.

\begin{abstract}
Проведены экспериментальные исследования импульсных электронных пучков с высокой локальной плотностью. Показано, что в вакуумных и газовых диодах при наносекундной и субнаносекундной длительности импульса тока пучка и уменьшении межэлектродного зазора реализуются условия, при которых наблюдается кумуляция плотности энергии при взаимодействии электронов с анодом. Установлено, что средняя энергия электронов при филаментации и самофокусировке пучка электронов в вакуумном диоде ускорителя с током $\sim 2 \mathrm{kA}$ и напряжением холостого хода $\sim 400 \mathrm{kV}$ составляет $50-100 \mathrm{keV}$, а плотность энергии $10^{9}-10^{10} \mathrm{~J} / \mathrm{cm}^{3}$. Подтверждено, что в газовом диоде плотность тока пучка может превышать $1 \mathrm{kA} / \mathrm{cm}^{2}$. Предполагается, что сверхплотные электронные пучки в вакуумных и газовых диодах образуются в результате лавинного размножения убегающих электронов в плазме катод-анодного зазора.
\end{abstract}

DOI: 10.21883/PJTF.2019.07.47526.17640

Созданием импульсных ускорителей электронов с энергиями в десятки-сотни $\mathrm{keV}$ занимались и продолжают заниматься во многих научных группах. Сильноточные электронные пучки (СЭП) нано- и субнаносекундной длительности с током $\sim 1 \mathrm{kA}$ и плотностью мощности $10^{6}-10^{8} \mathrm{~W} / \mathrm{cm}^{2}$ широко используются для различных приложений, в частности в радиационной физике и химии твердого тела $[1,2]$, для диагностики природных и искусственных кристаллов [3,4], инициирования взрывного разложения высокочувствительных энергетических материалов [5,6].

В последнее время появились новые задачи, требующие реализации более высоких плотностей мощности электронных пучков $\sim 10^{10}-10^{12} \mathrm{~W} / \mathrm{cm}^{2}$. К ним можно отнести разработку методов атомной спектроскопии с испарением пробы СЭП, инициирование взрывного разложения слабочувствительных бризантных взрывчатых веществ, генерацию мощных ударных волн с интенсивностью, достаточной для откольного разрушения металлических мишеней. Часть этих задач была решена с применением явления самофокусировки СЭП, генерируемого в вакуумном диоде ускорителя электронов с генератором ГИН-600 [2]. Следует отметить, что исследования явления самофокусировки ранее обычно проводились с использованием релятивистских электронных пучков (РЭП) с током, превышающим ток Альфвена: $I_{A}=17 \beta \gamma$, где $\beta=v / c, \gamma=1 /\left(1-\beta^{2}\right)^{1 / 2}-$ релятивистский фактор, $v-$ скорость электронов пучка, $c$ - скорость света. В экспериментах с РЭП ток составлял 100-200 kA и значительно превышал ток Альфвена ( 20kA) [7-9]. Было показано, что пучок фокусируется собственным магнитным полем, при этом первостепенную роль играет плазма, образующаяся в катод-анодном промежутке. Что касается механизмов, ответственных за явления филаментации и самофокусировки электронного пучка в вакуумном диоде электронного ускорителя, ток которого значительно меньше тока Альфвена, то они до сих пор не выяснены и требуют специальных исследований.

Следует отметить, что неоднородности плотности тока при вакуумном пробое и эрозия анода наблюдались и при токах менее 500 А [10]. Были зарегистрированы микроканалы от острия отрицательной и положительной полярности, а также повреждение поверхности плоского электрода при разряде в воздухе атмосферного давления [11]. Увеличение плотности тока пучка убегающих электронов наблюдалось при уменьшении давления в диодах, заполненных различными газами [12]. Таким образом, из опубликованных работ известно о фокусировке тока пучка в вакуумных, а также в газовых диодах. Однако экспериментальных результатов изучения воздействия на анод при токах ускорителей $\sim 1 \mathrm{kA}$ весьма мало.

Цель настоящей работы - изучить условия получения филаментированных электронных пучков с большой локальной плотностью тока в вакуумных и газовых диодах и по результатам исследований оценить их характеристики: пространственное распределение, энергию электронов, а также плотность энергии.

Эксперименты были проведены на двух установках. В установке № 1 (максимальная энергия электронов $T \sim 400 \mathrm{keV}$, длительность импульса тока на полувысоте $\tau_{0.5}=12 \mathrm{~ns}$, наибольший ток пучка за Al-фольгой толщиной $20 \mu \mathrm{m} I_{\max } \approx 2 \mathrm{kA}$ ) использовался генератор ГИН-600 [13], к которому подключался вакуумный диод. Вакуумный диод был образован трубчатым катодом и 

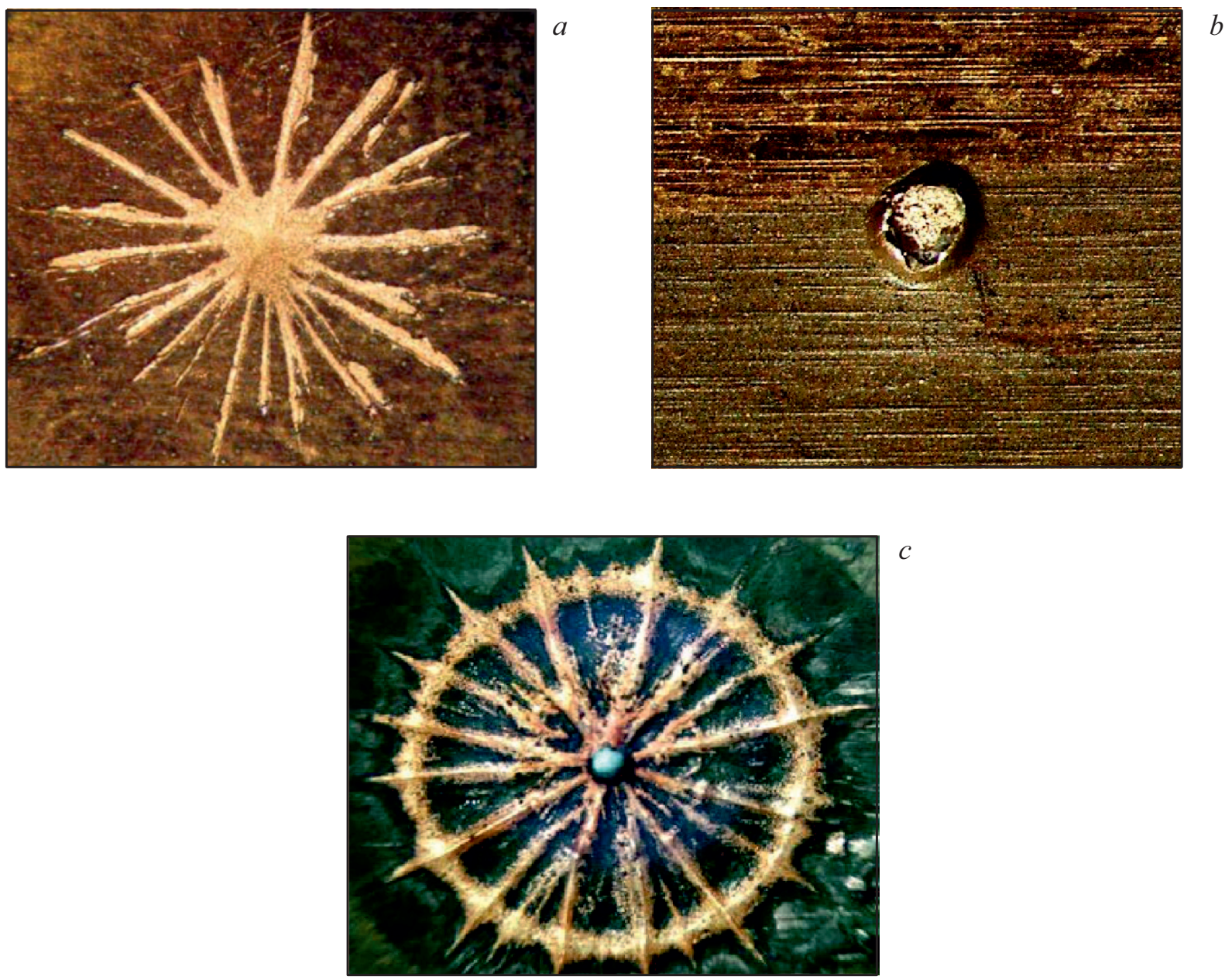

Рис. 1. Фотографии эрозионных следов отдельных токовых каналов „автографов“, образовавшихся на поверхности анодов при облучении СЭП в режиме филаментации и самофокусировки в вакуумном диоде ускорителя с генератором ГИН-600. $a, b-$ фотографии облучаемой и тыльной поверхностей медной фольги толщиной $180 \mu \mathrm{m}$ за один импульс облучения, $c-$ эрозионный след на поверхности медной пластины толщиной $2 \mathrm{~mm}$ после многоимпульсного облучения.

плоским анодом. Аспектное отношение $g=R / d$ (где $R$ - радиус катода, $d-$ межэлектродный зазор) варьировалось в диапазоне 0.7-1. Процесс фокусировки исследовался по следам эрозии на анодных пластинах из различных металлов (,автографам“ электронного пучка) с помощью оптической микроскопии с пространственным разрешением $\sim 10 \mu \mathrm{m}$.

В установке № $2\left(T \sim 250 \mathrm{keV}, \tau_{0.5} \approx 0.1-0.5 \mathrm{~ns}\right.$, $I_{\max } \approx 100-500$ А) использовался генератор СЛЭП-150, к которому подключался газовый диод [12]. Длительность импульса тока сверхкороткого лавинного электронного пучка (СЛЭП) на полувысоте зависела от давления азота. Катод также был выполнен в виде трубки диаметром $6 \mathrm{~mm}$. Анод газового диода был выполнен из сетки с прозрачностью 64\% по свету, на которую помещалась Al- или AlBe-фольга. Аспектное отношение варьировалось в диапазоне 0.25-1.5. В ряде экспериментов фольга убиралась и через сетку можно было регистрировать форму разряда. При фотографировании „автографов““ электронного пучка за сеткой и Al-фольгой устанавливался люминофор, а за ним помещалось окно из кварца. Газовый диод откачивался форвакуумным насосом и заполнялся азотом. Максимальные амплитуды тока пучка достигались при давлениях азота в единицы $\mathrm{kPa}$.

Наиболее интересные результаты по воздействию пучка электронов на анод были получены при филаментации и самофокусировке СЭП в вакуумном диоде. Характерные следы эрозии („автографы“ электронного пучка), образующиеся на поверхности медного анода за один импульс облучения при величине катод-анодного зазора $d=3 \mathrm{~mm}$ и радиусе полого цилиндрического катода $R=3 \mathrm{~mm}$, приведены на рис. $1, a$.

Видно, что в результате единичного импульса воздействия на поверхности анода формируется геометрическая фигура, напоминающая „звезду“, среднее число „лучей“ ры $\sim 7-8 \mathrm{~mm}$. Более детальное изучение ,автографа“, полученного на медной фольге толщиной $180 \mu \mathrm{m}$, позволило определить геометрические параметры отдель- 

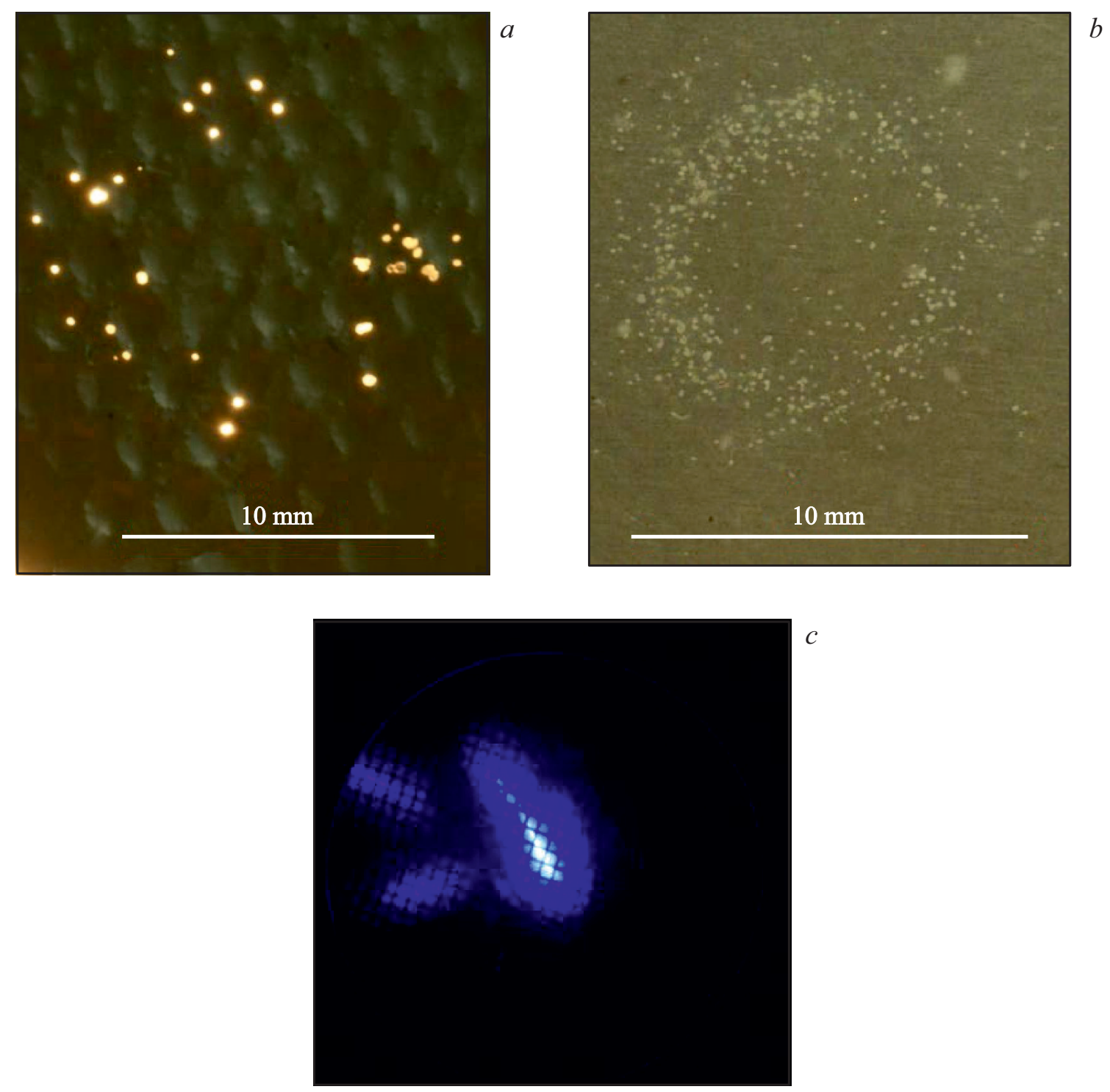

Рис. 2. Фотографии повреждений анодной фольги $(a, b)$ и свечения люминофора $(c)$ за фольгой под воздействием пучка электронов. $a$ - азот, 760 Torr, зазор $4 \mathrm{~mm}$, фольга Al $(10 \mu \mathrm{m}), 20$ импульсов; $b$ - азот, 760 Torr, зазор $8 \mathrm{~mm}$, фольга AlBe $(60 \mu \mathrm{m}), 200$ импульсов; $c$ - азот, 9 Torr, зазор $12 \mathrm{~mm}$, фольга $\mathrm{Al}(10 \mu \mathrm{m}), 1$ импульс.

ных „лучей“: ширина эрозионного следа изменялась в пределах $\sim(70-150) \mu \mathrm{m}$, глубина $\sim(10-15) \mu \mathrm{m}$, диаметр центрального кратера $\sim 1.0-1.5 \mathrm{~mm}$. При этом на тыльной стороне медной мишени наблюдался откол (рис. $1, b)$. В латунном аноде толщиной $60 \mu \mathrm{m}$ за один импульс образовывалось отверстие диаметром $\sim 1.3 \mathrm{~mm}$. Многоимпульсное облучение медного анода толщиной в $2 \mathrm{~mm}$ приводило к появлению на периферии „лучей“ эрозионного кольца (рис. 1,c). На отдельных фотографиях „автографов“ наблюдалось слияние двух близкорасположенных ,лучей“ в один. Одновременно с „лучами“ на облучаемой поверхности мишеней часто формируются локальные эрозионные следы (незавершенные „лучи“), вытянутые в направлении от периферии к центру пятна самофокусировки.
В экспериментах с алюминиевым анодом толщиной $100 \mu \mathrm{m}$ в пятне самофокусировки за один импульс наблюдались отколы как на тыльной, так и на облучаемой поверхности с формированием сквозного отверстия. При этом „розетка“ разрыва, расположенная на тыльной поверхности мишени, раскрывалась в направлении распространения электронного пучка, а „розетка“, расположенная на облучаемой поверхности, - навстречу электронному пучку. Следовательно, максимум энерговыделения самосфокусированного электронного пучка был расположен близко к центру облучаемой мишени (т.е. на глубине $\sim 40-50 \mu \mathrm{m})$, что и приводит к одновременному отколу как облучаемой, так и тыльной поверхности мишени с формированием сквозного отверстия. Из экспериментально определенных величин 
(максимума энерговыделения в алюминиевой мишени и откольной прочности меди) были оценены средняя энергия электронов в филаментах и объемная плотность энергии в пятне самофокусировки, которые составили $50-100 \mathrm{keV}$ и $10^{9} \mathrm{~J} / \mathrm{m}^{3}$ соответственно.

Полная энергия электронного пучка с генератором СЛЭП-150 была меньше на два порядка при малых давлениях в газовом диоде и в $10^{4}$ раз при давлении азота $100 \mathrm{kPa}$, чем в случае электронного пучка с генератором ГИН-600. Однако и в этих условиях наблюдалось повреждение анодной фольги как при уменьшении межэлектродного зазора, так и при уменьшении давления в диоде. При этом при уменьшении межэлектродного зазора повреждение фольги наблюдалось в более широком диапазоне давлений. На рис. 2, $a$ показаны отверстия в Al-фольге толщиной $10 \mu \mathrm{m}$ при межэлектродном зазоре $4 \mathrm{~mm}$ и давлении азота $100 \mathrm{kPa}$. На рис. 2, $b$ приведены автографы электронного пучка при межэлектродном зазоре $8 \mathrm{~mm}$ и давлении азота $100 \mathrm{kPa}$. Толщина фольги и число импульсов были увеличены.

При увеличении межэлектродного зазора до $12 \mathrm{~mm}$ и давлении азота $11.8-100 \mathrm{kPa}$ разряд состоял из нескольких диффузных струй, имеющих форму конуса с диаметром основания в несколько миллиметров, которые начинались с катода. На фотографиях интегрального свечения разряда в азоте и других газах яркие пятна обычно были видны только на кромке катода. В этих условиях повреждения анода из Al-фольги не наблюдалось. „Автограф“тока пучка, полученный по свечению люминофора за Al-фольгой, представляет собой равномерно распределенное по поверхности анода свечение. Однако уменьшение давления в газовом диоде приводило к появлению диффузных каналов и фокусировке тока пучка. На рис. 2, с показано свечение люминофора при давлении $1.2 \mathrm{kPa}$ и зазоре $12 \mathrm{~mm}$. В центре фольги видно яркое пятно, которое наблюдалось и за толстыми фольгами из $\mathrm{Al}$, что подтверждает генерацию убегающих электронов с высокой энергией.

Проведенные исследования показывают, что в вакуумных и газовых диодах при общем токе в сотни ампер-единицы килоампер возникают условия (прежде всего при уменьшении межэлектродных зазоров и образовании анодной плазмы), при которых происходит существенное увеличение плотности тока пучка. При этом продолжается генерация электронов с высокой энергией и повреждается анод. В вакуумном диоде с генератором ГИН-600 генерация пучков электронов большой плотности приводила к эрозии поверхности анодов и образованию отверстий в тонких фольгах, а также отколов с прямой и обратной стороны, в том числе при одном импульсе тока пучка. Так, при подборе толщины Al-фольги отколы были получены одновременно с обеих сторон облучаемой мишени.

На основании результатов, полученных в настоящей работе, и известных данных по самофокусировке плотных сильноточных РЭП [7-9,14] можно представить последовательность процессов, приводящих к филамента- ции и самофокусировке электронного пучка в вакуумном диоде электронного ускорителя с генератором ГИН-600. В начале процесса, до появления анодной плазмы, в диоде с полым цилиндрическим катодом наблюдается ламинарный поток электронов, формируемый из катодной плазмы. Под действием электронной бомбардировки возникает анодная плазма, которая образуется в результате десорбции газов с поверхности анода и испарения диэлектрических и полупроводниковых включений с последующей их ионизацией. При взаимодействии электронного пучка с анодной плазмой развивается нитевидная неустойчивость, приводящая к филаментации электронного пучка (разбиению его на 18-20 нитей токовых каналов). По-видимому, как и в случае РЭП с большими токами, каждый канал привязан к центру взрывной электронной эмиссии. По мере роста тока в филаментах за счет лавинообразного размножения быстрых электронов величина магнитного поля возрастает, что приводит к схлопыванию филаментированных микропучков в центральное пятно фокусировки. Таким образом, в вакуумном диоде формируются два электронных пучка с различными пространственно-временны́ми и энергетическими характеристиками: однородный высокоэнергетический и филаментированный с меньшей энергией электронов.

В газовых диодах происходят подобные процессы, начало которых облегчается наличием газа в диоде. Мы полагаем, что наиболее вероятным механизмом генерации сверхплотных филаментированных электронных пучков в вакуумных и газовых диодах является пробой на убегающих электронах, развивающийся в плазме катод-анодного зазора.

В заключение отметим, что повреждение внутренней поверхности камеры, которая заполняется дейтерием и тритием в установках типа ТОКАМАК [15], также может происходить за счет филаментации и самофокусировки пучков убегающих электронов.

Работа выполнена в рамках проекта Российского научного фонда № 18-19-00184 и частично за счет гранта Программы повышения конкурентоспособности Томского политехнического университета (номер проекта ВИУ_ИФВТ_73/2017).

\section{Список литературы}

[1] Высокоэнергетическая электроника твердого тела / Под ред. Д.И. Вайсбурда. Новосибирск: Наука, 1982. 227 с.

[2] Олешко В.И. Пороговые процессы в твердых телах при взаимодействии с сильноточными электронными пучками. Докт. дис. Томск, 2009. $317 \mathrm{c}$.

[3] Соломонов В.И., Михайлов С.Г. Импульсная катодолюминесценция и ее применение для анализа конденсированных веществ. Екатеринбург: УрО РАН, 2003. 182 с.

[4] Sorokin D.A., Burachenko A.G., Beloplotov D.V., Tarasenko V.F., Baksht E.Kh., Lipatov E.I., Lomaev M.I. // J. Appl. Phys. 2017. V. 122. N 15. P. 154902. 
[5] Кригер В.Г., Каленский А.В. // Хим. физика. 1995. Т. 14. № 4. C. $152-160$.

[6] Олешко В.И., Зарко В.Е., Лысык В.В., Ципилев В.П., Калмыков П.И. // Письма в ЖТФ. 2015. Т. 41. В. 11. C. $10-15$.

[7] Ликсонов В.Д., Сидоров Ю.Л., Смирнов В.П. // Письма в ЖЭТФ. 1974. Т. 19. В. 8. С. 516-520.

[8] Goldstein S.A., Davidson R.C., Siambis J.G., Roswell L. // Phys. Rev. Lett. 1974. V. 33. N 25. P. 1471-1474.

[9] Тарумов Э.Э. Получение и фокусировка сильноточных релятивистских электронных пучков в диодах // Генерация и фокусировка сильноточных релятивистских электронных пучков / Под ред. Л.И. Рудакова. М.: Энергоатомиздат, 1990. С. $122-181$.

[10] Проскуровский Д.И., Ротштейн В.И., Шубин А.Ф., Янкелевич Е.Б. // ЖТФ. 1975. Т. 45. В. 10. С. 2125-2143.

[11] Алмазова К.И., Белоногов А.Н., Боровков В.В., Горелов Е.В., Морозов И.В., Тренькин А.А., Харитонов С.Ю. // ЖТФ. 2018. Т. 88. В. 6. С. 827-831.

[12] Бураченко А.Г., Тарасенко В.Ф., Костыря И.Д., Бакum E.X. // Оптика атмосферы и океана. 2017. Т. 30. № 10. C. $883-887$.

[13] Ковальчук Б.М., Месяи, Г.А., Семин Б.М., Шпак В.Г. // ПТЭ. 1981. № 4. С. 15-18.

[14] Welch D.R., Rose D.V., Oliver B.V., Schamiloglu E., Hahn K., Maenchen J.E. // Phys. Plasmas. 2004. V. 11. N 2. P. 751-760.

[15] Savrukhin P.V., Shestakov E.A. // Nucl. Fusion. 2015. V. 55. N 4. P. 043016. 